\title{
Progress in the Growth of Yb:S-FAP Laser Crystals
}

K. I. Schaffers, J. B. Tassano, P. A. Waide, S. A. Payne, and R. Morris

This article was submitted to

$12^{\text {th }}$ American Conference on Crystal Growth and Epitaxy, Vail, Colorado, August 13-18, 2000

\section{July 1, 2000}

U.S. Department of Energy

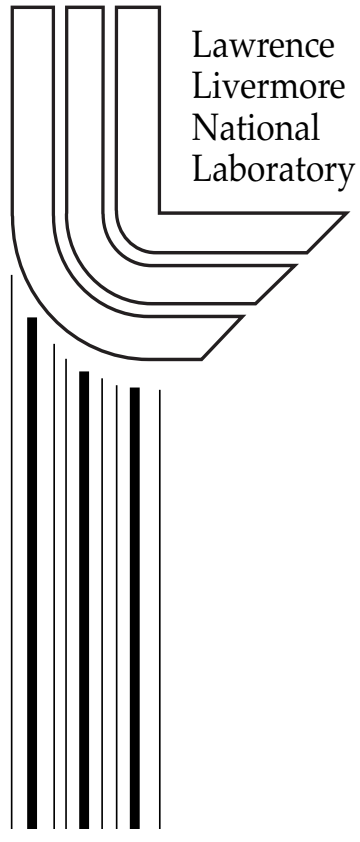




\section{DISCLAIMER}

This document was prepared as an account of work sponsored by an agency of the United States Government. Neither the United States Government nor the University of California nor any of their employees, makes any warranty, express or implied, or assumes any legal liability or responsibility for the accuracy, completeness, or usefulness of any information, apparatus, product, or process disclosed, or represents that its use would not infringe privately owned rights. Reference herein to any specific commercial product, process, or service by trade name, trademark, manufacturer, or otherwise, does not necessarily constitute or imply its endorsement, recommendation, or favoring by the United States Government or the University of California. The views and opinions of authors expressed herein do not necessarily state or reflect those of the United States Government or the University of California, and shall not be used for advertising or product endorsement purposes.

This is a preprint of a paper intended for publication in a journal or proceedings. Since changes may be made before publication, this preprint is made available with the understanding that it will not be cited or reproduced without the permission of the author.

This report has been reproduced directly from the best available copy.

Available electronically at http://www.doc.gov/bridge

Available for a processing fee to U.S. Department of Energy

And its contractors in paper from

U.S. Department of Energy

Office of Scientific and Technical Information

P.O. Box 62

Oak Ridge, TN 37831-0062

Telephone: (865) 576-8401

Facsimile: (865) 576-5728

E-mail: reports@adonis.osti.gov

Available for the sale to the public from

U.S. Department of Commerce

National Technical Information Service

5285 Port Royal Road

Springfield, VA 22161

Telephone: (800) 553-6847

Facsimile: (703) 605-6900

E-mail: orders@ntis.fedworld.gov

Online ordering: http:/ / www.ntis.gov/ordering.htm

\section{OR}

Lawrence Livermore National Laboratory

Technical Information Department's Digital Library

http: / / www.llnl.gov/tid/Library.html 


\title{
Progress in the Growth of Yb:S-FAP Laser Crystals
}

\author{
K. I. Schaffers, * J. B. Tassano, P. A. Waide, S. A. Payne, and R. C. Morris \\ *Lawrence Livermore National Laboratory, PO Box 808, L-482, Livermore, CA 94551 \\ Telephone: (925) 422-5084, Fax: 925-423-6195, schaffers1@llnl.gov
}

\begin{abstract}
The crystal growth of $\mathrm{Yb}: \mathrm{S}-\mathrm{FAP}\left[\mathrm{Yb}^{3+}: \mathrm{Sr}_{5}\left(\mathrm{PO}_{4}\right)_{3} \mathrm{~F}\right]$ is being studied for $1.047-\mu \mathrm{m}$ laser operation. These crystals are not yet routinely available and the growth of high optical quality, low loss crystals poses a challenge due to a number of crystal growth issues, including, cloudiness, bubble core defects, anomalous absorption, low-angle grain boundaries, and cracking. At this time, a growth process has been formulated to simultaneously eliminate or greatly diminish each of the defects yielding high quality material. Laser slabs of dimension 4.0 x $6.0 \times 0.75 \mathrm{~cm}$ are being fabricated from sub-scale pieces using the diffusion bonding technique.
\end{abstract}

Keywords: Ytterbium lasers, Yb:S-FAP, Apatite analogs, Czochralski growth

\section{Introduction}

Host materials doped with the $\mathrm{Yb}^{3+}$ ion have sparked a great deal of interest in the last several years for their use as solid-state lasers that can be pumped by InGaAs-based diode lasers.

[1] These materials have longer storage lifetimes than $\mathrm{Nd}^{3+}$-doped hosts and can have favorable cross-sections. [2] For example, the material and laser performance have been examined for Yb:YAG [3] and the Yb:fluoroapatite (FAP) family of crystals [4-6] including, $\mathrm{Ca}_{5}\left(\mathrm{PO}_{4}\right)_{3} \mathrm{~F}(\mathrm{C}-$ FAP), $\mathrm{Sr}_{5}\left(\mathrm{PO}_{4}\right)_{3} \mathrm{~F}(\mathrm{~S}-\mathrm{FAP}), \mathrm{Ca}_{5-\mathrm{x}} \mathrm{Sr}_{\mathrm{x}}\left(\mathrm{PO}_{4}\right)_{3} \mathrm{~F}, \mathrm{Sr}_{5-\mathrm{x}} \mathrm{Ba}_{\mathrm{x}}\left(\mathrm{PO}_{4}\right)_{3} \mathrm{~F}$, and $\mathrm{Sr}_{5}\left(\mathrm{VO}_{4}\right)_{3} \mathrm{~F}$. Although $\mathrm{Yb}: \mathrm{YAG}$ is much better suited for high power/high thermal load operations because of its 
significantly better thermal properties, Yb:fluoroapatites are well suited for diode pumping in moderate thermal load applications owing to the relaxed diode brightness requirement and the $3 \mathrm{x}$ greater gain cross-section. The laser performance of Yb:S-FAP has been investigated for use in a diode pumped gas-cooled-slab laser geometry. [7] It was shown to produce 50W of optical power at $1047 \mathrm{~nm}$ with a laser output efficiency of $51 \%$ with a laser-diode array pump source operating at $900 \mathrm{~nm}$. Currently there is interest in this crystal for a $100 \mathrm{~J}, 1 \mathrm{~kW}, 1 \mathrm{~ns}$ gas-cooled slab laser system (Mercury Laser). [8] Yb:S-FAP crystals are not yet routinely available and the growth of high optical quality, low loss crystals poses a challenge due to a number of crystal growth issues, including cloudiness, bubble core defects, anomalous absorption, cracking, and low-angle grain boundaries. A significant effort has been made to understand the defect chemistry of Yb:S-FAP and a growth process has been developed to yield high optical quality crystals.

\section{Experimental}

Crystals of Yb:S-FAP are grown by using the Czochralski method from a $\mathrm{SrF}_{2}$-rich melt. Growth is done in a four inch diameter by four inch tall iridium crucible at $1810^{\circ} \mathrm{C}$ in an inert flowing nitrogen atmosphere with rotation rates from 6-15 rpm and a pull rate of $0.5 \mathrm{~mm} / \mathrm{hr}$. As described later in this article, excess $\mathrm{SrF}_{2}$ in the melt has been chosen because it produces clear crystals with no cloudiness. The melt is prepared by decomposing $\mathrm{SrHPO}_{4}, \mathrm{SrCO}_{3}$, and $\mathrm{Yb}_{2} \mathrm{O}_{3}$ starting materials to yield a $\mathrm{Yb}$-doped $\left.\mathrm{Sr}_{3} \mathrm{PO}_{4}\right)_{2}$ melt to which $\mathrm{SrF}_{2}$ is added to yield the appropriate composition. The pre-decomposition reaction prevents $\mathrm{SrF}_{2}$ from oxidizing to $\mathrm{SrO}$ thereby removing fluorine from the melt. $\mathrm{Yb}_{2} \mathrm{O}_{3}$ has been typically used as the dopant to aid in the charge compensation process where a $\mathrm{Yb}^{3+}-\mathrm{O}^{2-}$ ion pair exchanges for a $\mathrm{Sr}^{2+}-\mathrm{F}^{-}$pair. [9] $\mathrm{An}$ excess of $\mathrm{Yb}_{2} \mathrm{O}_{3}$ is added to the starting composition to accommodate the approximate $12 \%$ 
distribution coefficient from melt to crystal. Current boule dimensions are $2.8 \mathrm{~cm}$ diameter by 7 $\mathrm{cm}$ length grown along the c-axis. Efforts are centered around growing crystals of sufficient size to produce pieces for diffusion bonding to form a $4.0 \mathrm{~cm}$ x $6.0 \mathrm{~cm}$ (c-axis) $\mathrm{x} 0.75 \mathrm{~cm}$ slab for the Mercury Laser being developed at Lawrence Livermore National Laboratory.

\section{Defect Chemistry and Growth Strategies}

A number of defect structures in Yb:S-FAP crystals have been overcome to produce high quality material for laser slabs. Five prominent defects encountered are, cloudiness in as-grown boules, bubble core defects, low-angle grain boundaries, anomalous absorption, and cracking; all are illustrated in Figure 1. An understanding of each of these defects has been achieved in an effort to engineer methods to eliminate or sufficiently reduce their magnitude to lessen the threat to laser performance.

A $\mathrm{SrF}_{2}$-rich melt composition has proven effective in eliminating the cloudiness in boules of Yb:S-FAP grown from a near-stoichiometric melt. The cloudiness is believed to be a result of second-phase particles that precipitate out in the crystal lattice. The identity of the second phase has not yet been verified, but it is likely of phosphate-based origin resulting from a deficiency of $\mathrm{SrF}_{2}$ at the growth interface with the evaporation from the melt surface. As a result, an excess of $\mathrm{SrF}_{2}$ beyond the stoichiometric composition is added to yield 33 mole percent total fluoride in the melt. A 33 mole percent $\mathrm{SrF}_{2}$ composition in the $\mathrm{Sr}_{3}\left(\mathrm{PO}_{4}\right)_{2}: \mathrm{SrF}_{2}$ phase system is equivalent to a congruently melting compound with the stoichiometry $\mathrm{Sr}_{7}\left(\mathrm{PO}_{4}\right)_{4} \mathrm{~F}_{2}$. However, InductivelyCoupled Plasma/Mass Spectrometry has identified the composition of the crystals to be $\mathrm{Sr}_{5}\left(\mathrm{PO}_{4}\right)_{3} \mathrm{~F}$. These phase relationships have been extrapolated from the $\mathrm{Ca}_{3}\left(\mathrm{PO}_{4}\right)_{2}: \mathrm{CaF}_{2}$ phase diagram [10] since the phase diagram for the strontium analog does not yet exist. It has been found that the amount of excess $\mathrm{SrF}_{2}$ that is added is significant where $<33$ mol\% yields cloudy 
crystals and large excesses lead to the formation of new, long "string-type" defects that propagate perpendicular to the c-axis at the core. However, compositions near $33 \mathrm{~mol} \%$ are optimal for eliminating the supersaturation of the second phase and clear crystals are produced.

A growth orientation along the c-axis for $\mathrm{Yb}$ :S-FAP crystals is critical for eliminating the anomalous absorption that occurs as a broad band from approximately 925-1000 nm with a peak at $975 \mathrm{~nm}$. Crystals grown along both the a-axis and $45^{\circ}$ to the c-axis intermittently display the unwanted absorption whereas there is no evidence for this absorption in the c-axis boules that have been grown to date. The absorption is attributed to the $\mathrm{Yb}^{3+}$ ion on a second site in the crystal lattice, based on excitation and emission spectra. The spectrum most closely resembles that of $\mathrm{Yb}^{3+}$ in a phosphate environment such as is seen in $\mathrm{LuPO}_{4}$ [2], where there are no characteristics of the desired spectrum arising from the vibration interactions of the $\mathrm{Yb}^{3+}-\mathrm{O}^{2-}$ charge compensation pair. [9] A possible explanation for the elimination of the anomalous absorption in c-axis crystals relates to the presence of $\mathrm{F}^{-}$ion "conduction" channels that parallel the c-axis in the apatite lattice. The preferred orientation may allow for easier charge compensation substitution of the $\mathrm{Yb}^{3+}-\mathrm{O}^{2-}$ pair for the $\mathrm{Sr}^{2+}-\mathrm{F}^{-}$pair giving rise to the appropriate absorption spectrum thereby reducing the probability of $\mathrm{Yb}$ achieving charge compensation by another mechanism.

By growing "seed extensions" and choosing a small cone angle to maintain a stable growth interface, low-angle grain boundaries have been eliminated. The grain boundaries appear as slight shifts in the refractive index or waves running through the crystal in sheets oriented perpendicular to the c-axis (see Figure 1). Reference 11 provides an extensive explanation of the crystal lattice effects that lead to the formation of these grain boundaries and therefore, these effects will not be reiterated here. However, it is understood that the dislocations are formed by 
propagation from the seed to the crystal and strain-induced deformations from an unstable growth interface. [12] The growth of a seed extension makes it possible to grow out any grain boundaries propagating from the seed or formed during the seeding process. In addition, a gradual increase in diameter in the cone section helps to maintain stable growth conditions reducing hoop stress preventing new grain boundaries from forming. Further, c-axis growth makes it easier to grow out grain boundaries because they propagate perpendicular to the growth direction.

Crystals of Yb:S-FAP are grown in a higher thermal gradient furnace and at small $2-3 \mathrm{~cm}$ diameter to stabilize the growth interface and control the formation of bubble core defects. The bubble core is attributed to constitutional supercooling where a supercooled liquid is formed from concentration gradients of rejected melt components pushed along in front of the advancing interface. In the $\mathrm{Yb}: \mathrm{S}-\mathrm{FAP}$ system, $\mathrm{SrF}_{2}$ and $\mathrm{Yb}_{2} \mathrm{O}_{3}$ are in excess to alleviate cloudiness and account for the distribution coefficient of dopant, respectively, and therefore, may be of higher concentration near the interface after being turned away from the growing crystal. Instabilities deviating from steady-state conditions, resulting from this phenomena, can then cause small protuberances that can come in contact with the supercooled liquid and grow very fast away from the interface into the melt. Eventually these protuberances grow together and close off, trapping low melting temperature liquid, which contracts and leaves a void upon cooling (see Figure 2). SEM/EDX analysis has pinpointed the approximate composition associated with the bubbles to be $\mathrm{Yb}_{2} \mathrm{O}_{3}$ and $\mathrm{Sr}_{3}\left(\mathrm{PO}_{4}\right)_{2}$. To prevent the growth of any protuberances formed at the interface, we have used higher thermal gradients, typically axial gradients of $\sim 35^{\circ} \mathrm{C} / \mathrm{cm}$ near the melt. In addition, it has been observed that the introduction of the bubble core consistently 
begins at diameters of approximately $\geq 3.0 \mathrm{~cm}$. Recent growths of smaller, $2.2 \mathrm{~cm}$ diameter boules, in the higher gradient have completely eliminated the bubble core defects.

Cracking is managed by not separating the crystals from the melt during the cooling process and by significant reduction of defects. The main source of cracking was related to high thermal gradients in the crystals, especially at larger $(5 \mathrm{~cm})$ diameters, as well as numerous bubble core defects. Cooling the crystals still attached to the melt reduces the thermal stress along the length of the boule by using the large thermal load of the melt to conduct heat into the crystal. As a result, cracking is no longer an issue in the growth of small diameter Yb:S-FAP crystals.

\section{Conclusions}

A growth process has been developed to eliminate each of the five defects encountered in $\mathrm{Yb}: \mathrm{S}-\mathrm{FAP}$ crystals. Excess $\mathrm{SrF}_{2}$ in the initial melt and c-axis growth have been successful in preventing cloudiness and the anomalous absorption. Also, seed extensions, higher thermal gradients, and small diameter crystals have proven effective in handling the formation of grain boundaries and bubble core defects. Finally, with the significant reduction in defects together with cooling the crystals while attached to the melt, cracking is no longer an issue. Boules grown using this recipe yield small crystals with high optical quality, as shown in Figure 3 . The diffusion bonding technology will be used to stitch together sub-slabs to form a full size (4 x 6 cm) slab. [13] This process has been proven successful in test samples where there is no evidence of the bond visibly or by using interferometry. Currently, high quality sub-slabs are being produced for laser testing. 


\section{Acknowledgements}

The authors wish to acknowledge Scientific Materials, Inc., for their collaborative work on this project and for performing the SEM/EDX measurements that identified the bubble core defects. We greatly appreciate the help of Camille Bibeau and Andrew Bayramian for their advice and for performing all of the spectroscopy and interferometry throughout the development of Yb:S-FAP crystals. In addition, we are indebted to Peter Thelin, Ron Vallene, and James Embree, for their expertise in cutting and polishing crystals for inspection and optical studies.

*Work done under the auspices of the U.S. Department of Energy by the University of California Lawrence Livermore National Laboratory under Contract W-7405-ENG-48.

\section{References}

[1] A. R. Reinberg, L. A. Riseberg, R. M. Brown, R. W. Wacker, and W. C. Holton, Appl. Phys. Lett. 19 (1971) 11; and T. Y. Fan, Opt. Lett. 16 (1991) 1089.

[2] L. D. DeLoach, S. A. Payne, L. L. Chase, L. K. Smith, W. L. Kway, and W. F. Krupke, IEEE J. Quantum Electron. 29 (1993) 1179.

[3] T. Y. Fan, S. Klunk, and G. Henien, Opt. Lett. 18 (1993) 423.

[4] S. A. Payne, L. K. Smith, L. D. DeLoach, W. L. Kway, J. B. Tassano, and W. F. Krupke, IEEE J. Quantum Electron. 30(1) (1994) 170.

[5] C. D. Marshall, L. K. Smith, R. J. Beach, M. A. Emanuel, K. I. Schaffers, J. Skidmore, S. A. Payne, and B. H. T. Chai, IEEE J. Quantum Electron. 32(4) (1996) 650.

[6] K. I. Schaffers, A. J. Bayramian, C. D. Marshall, J. B. Tassano, and S. A. Payne, OSA Trends in Optics and Photonics on Advanced Solid State Lasers, Eds. C. R. Pollock and W. R. Bosenberg (January 1996 Conference) p. 420. 
[7] C. D. Marshall, L. K. Smith, S. Sutton, M. A. Emanuel, K. I. Schaffers, S. Mills, S. A. Payne, W. F. Krupke, and B. H. T. Chai, OSA Trends in Optics and Photonics on Advanced Solid State Lasers, Eds. S. A. Payne and C. R. Pollock (January 1996 Conference) p. 208.

[8] C. D. Marshall, R. J. Beach, C. Bibeau, C. A. Ebbers, M. A. Emanuel, E. C. Honea, W. F. Krupke, S. A. Payne, H. T. Powell, K. I. Schaffers, J. A. Skidmore, and S. B. Sutton, Advanced Solid State Lasers conference Technical Digest (1998) p. 76.

[9] L. D. DeLoach, S. A. Payne, W. L. Kway, J. B. Tassano, S. N. Dixit, and W. F. Krupke, J. Luminescence 62 (1994) 85.

[10] J. Berak and I. Tomczak-Hudyna, Rocz. Chem. 12 (1972) 2157.

[11] G. M. McManus, R. H. Hopkins, and W. J. Takei, J. Appl. Phys. 40(1) (1969) 180.

[12] Private communication with Robert Morris, consultant (1998).

[13] All diffusion bonding is done at Onyx Optics, Inc. in Dublin, CA.

\section{Figure Captions}

1. Five defect structures are present in Yb:S-FAP crystals including, (a) bubble core, (b) anomalous absorption, (c) cloudiness, (d) cracking, and (e) low-angle grain boundaries.

2. Photograph of the bubble core defects in Yb:S-FAP crystals at a magnification of $78 \mathrm{X}$.

3. Photograph of high quality Yb:S-FAP crystal and polished section for diffusion bonding. 
Figure 1

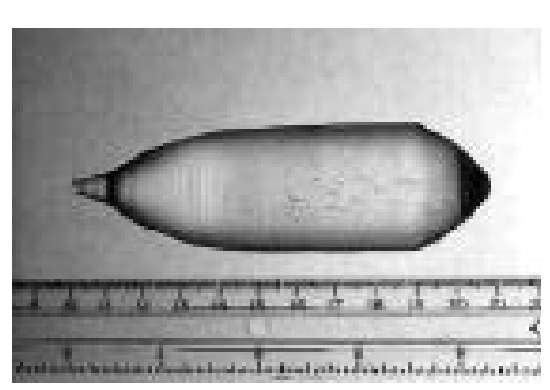

(a)

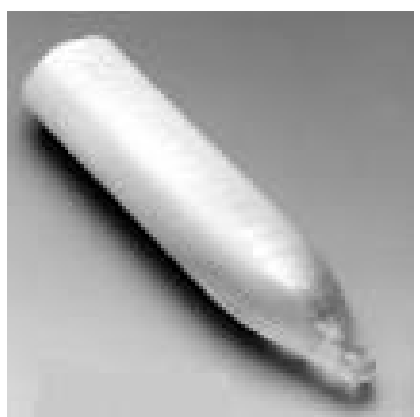

(c)

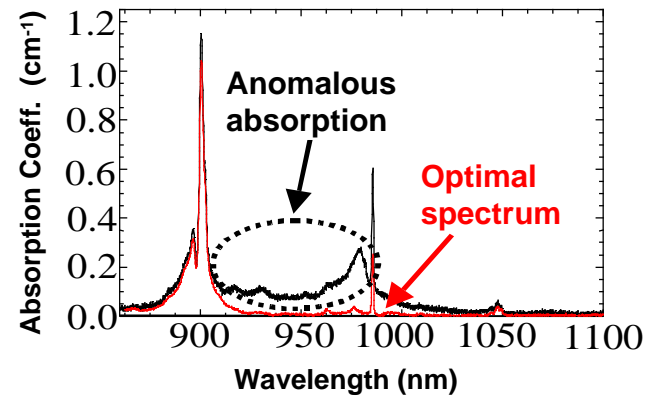

(b)

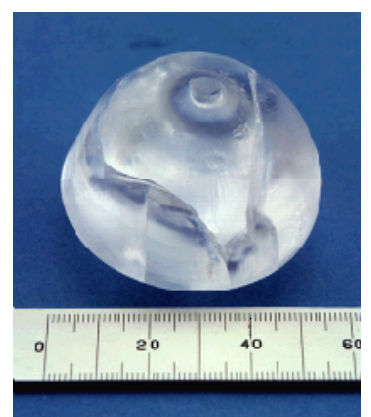

(d)

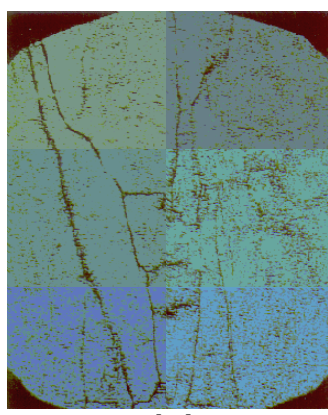

(e)

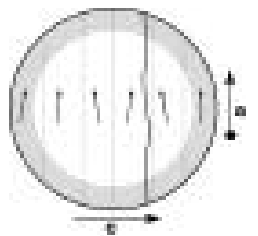


Figure 2

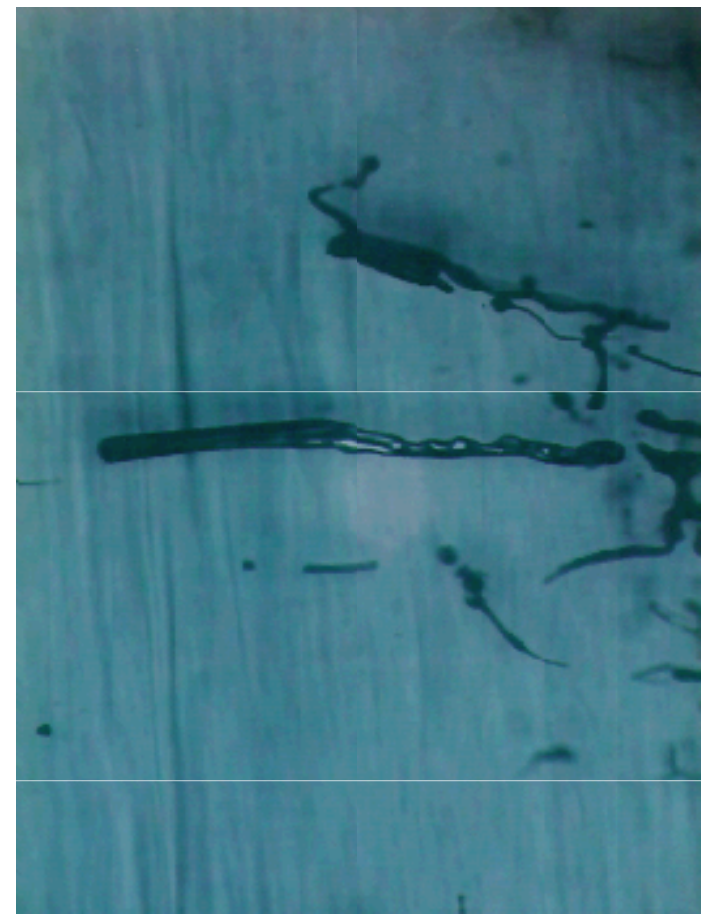


Figure 3

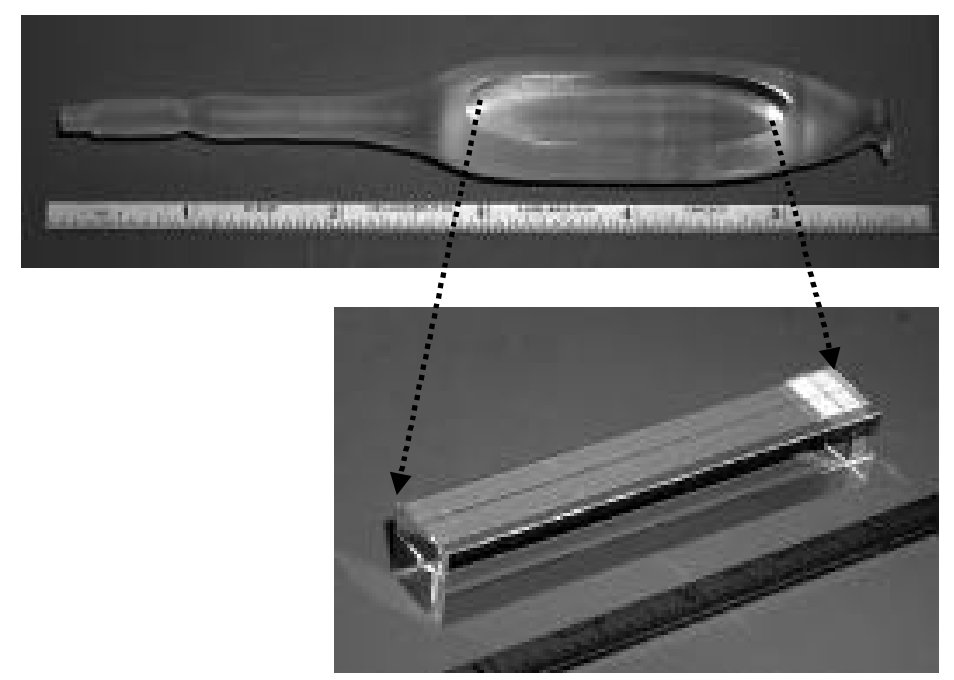

